\title{
Mitochondrial dysfunction in psychiatric morbidity: current evidence and therapeutic prospects
}

Lilach Toker'

Galila Agam ${ }^{2,3}$

'Department of Psychiatry, University of British Columbia, Vancouver, BC, Canada; ${ }^{2}$ Department of Clinical Biochemistry and Pharmacology, Ben-Gurion University of the Negev, Beer-Sheva, Israel; ${ }^{3}$ Mental Health Center, Beer-Sheva, Israel
Correspondence: Lilach Toker Department of Psychiatry, University of British Columbia, 177 Michael Smith Laboratories, 2185 East Mall, Vancouver, BC V6T IZ4, Canada

Email Itoker@mail.ubc.ca

\section{Galila Agam}

Department of Clinical Biochemistry and Pharmacology, Ben-Gurion University of the Negev, P.O Box 4500, Beer-Sheva 84170, Israel

Email galila@bgu.ac.il
This article was published in the following Dove Press journal:

Neuropsychiatric Disease and Treatment

24 September 2015

Number of times this article has been viewed
Abstract: Cumulating evidence for the involvement of mitochondrial dysfunction in psychiatric disorders leaves little to no doubt regarding the involvement of this pathology in mood disorders. However, mitochondrial abnormalities are also observed in a wide range of disorders spanning from cancer and diabetes to various neurodegenerative and neurodevelopmental disorders such as Parkinson's, Alzheimer's, Huntington's, autism, and amyotrophic lateral sclerosis. The apparent lack of specificity questions the role of mitochondrial dysfunction in psychiatric disorders, in general, and in mood disorders, in particular. Is mitochondrial dysfunction a general phenomenon, simplistically rendering brain cells to be more vulnerable to a variety of disease-specific perturbations? Or is it an epiphenomenon induced by various disease-specific factors? Or possibly, the severity and the anatomical region of the dysfunction are the ones responsible for the distinct features of the disorders. Whichever of the aforementioned ones, if any, is correct, "mitochondrial dysfunction" became more of a cliché than a therapeutic target. In this review, we summarize current studies supporting the involvement of mitochondrial dysfunction in different psychiatric disorders. We address the question of specificity and causality of the different findings and provide an alternative explanation for some of the aforementioned questions.

Keywords: bipolar disorder, psychiatric disorders, schizophrenia, Stanley Foundation Brain Collection

\section{Introduction - what does mitochondrial dysfunction stand for?}

The term "mitochondrial dysfunction" is used in the literature to represent different features associated with mitochondria. In some cases, the term may merely represent observed transcriptional changes. For example, some studies used this term in relation to altered expression of a few mitochondria-related genes. ${ }^{1,2}$ Based on gene enrichment analysis of the downregulated genes, Konradi et $\mathrm{al}^{3}$ reported mitochondrial dysfunction in Bipolar disorder (BP) but not schizophrenia (SCZ) patients. Others did find enrichment of mitochondrial function among downregulated genes in SCZ patients. ${ }^{4,5}$ The term is also used when relating to an increased number of mitochondrial DNA (mtDNA) mutations ${ }^{6}$ and mitochondrial structural abnormalities. ${ }^{7,8}$ In several studies, the authors used oxidative phosphorylation byproducts as indicators of mitochondrial function. For example, Gardner et $\mathrm{al}^{9}$ reported altered mitochondrial function in major depression (MD) based on decreased muscle adenosine triphosphate (ATP) in patients. Additional studies commonly cited as an evidence for mitochondrial dysfunction in psychiatry measured metabolites affected by mitochondrial function: eg, increased lactate and taurine levels were found in $\mathrm{SCZ}^{4}$ and $\mathrm{BP}$ patients; ${ }^{10,11} \mathrm{Du}$ et al measured 
high-energy phosphate-containing metabolites and found increased glycolysis-derived ATP in SCZ patients; ${ }^{12}$ and Frey et al reported decreased levels of total creatine in BP patients. ${ }^{13}$ Finally, activity of mitochondrial complexes was directly measured in a subset of the studies. ${ }^{14-16}$

While numerous studies use the term "mitochondrial dysfunction" when summarizing their findings, it is important to consider the impact of the reported mitochondria-related abnormality. Altered expression levels of mitochondrial genes/proteins in a whole tissue does not necessarily indicate abnormalities in the organelle's function. For example, mitochondria are enriched in the synapses of neurons, and are targeted toward axonal and dendritic synapses during synaptic activity. ${ }^{17,18}$ Decreased synaptic density of cortical pyramidal cells were reported in postmortem brain of SCZ patients. ${ }^{19,20}$ Thus, decreased level of mitochondrial genes/protein as well as mitochondrial mass might be a direct result of decreased synaptic density in these subjects rather than indicate altered mitochondrial function. In addition, some studies indicate alterations in the energetic state of the cell, while others, eg, those reporting altered morphology, might imply affected mitochondrial function that is unrelated to energy production ${ }^{8}$ (eg, calcium buffering) or that results in cellular damage due to an increased production of toxic compounds. Relating to, classifying, and understanding the specific mitochondria-related findings is crucial for appreciating the impact of these alteration on the pathophysiology of different psychiatric disorders.

\section{Mitochondrial dysfunction - an etiological factor or an epiphenomenon?}

Comorbidity of mitochondrial dysfunction and psychiatric disorders is well established, ${ }^{21-24}$ yet the causality between them is not well understood. Existence of common etiological factor does not corroborate with the different phenotypes and the different medication types for these disorders. In this section, we will discuss the findings supporting the role of mitochondria in the development and progression of psychiatric disorders and the possibility of mitochondrial dysfunction being an outcome of the disease.

Mitochondria are the main source for cellular energy obtained through synthesis of ATP in the oxidative phosphorylation process. Energy impairment in psychiatric disorders was reviewed in detail by Rezin et al. ${ }^{22}$ Beyond energy production, mitochondrial function includes other processes essential for cell function and viability. The most recognized are calcium buffering and homeostasis ${ }^{25-27}$ as well as apoptosis. ${ }^{28}$ Altered cellular calcium levels were reported in BP patients. ${ }^{29-31}$
Support for mitochondrial dysfunction exhibiting an etiological role in psychiatric disorders arises from animal studies. A neuron-specific mutation in mitochondrial DNA (mtDNA) polymerase (POLG), altering the proofreading function of the enzyme, modifies mouse behavior in mood disorder-related paradigms such as the circadian rhythm and the startle response. ${ }^{32}$ Mice harboring this mutation also exhibit altered monoamine levels and turnover in the amygdala and the hippocampus and an enhanced mitochondrial $\mathrm{Ca}^{2+}$ uptake. ${ }^{33}$ In our recent study, ${ }^{34}$ we induced mild mitochondrial dysfunction in mice by chronic treatment with low doses of rotenone, a mitochondrial complex I inhibitor. We found that such treatment affects several behavioral paradigms associated with facets of depression and mania. Interestingly, the rotenone-induced behavioral effects could be counteracted by chronic lithium treatment (the prototype mood stabilizer). Similar results using different inducers of mitochondrial dysfunction and different mood stabilizers have recently been shown by others. ${ }^{35,36}$

In the previous paragraph, we discussed evidence for mitochondrial dysfunction being an etiological factor of psychiatric-like behavioral aspects. However, other pieces of evidence suggest that this might not always be the case, proposing that mitochondrial dysfunction might reflect a consequence/epiphenomenon acquired during the course of the disease as discussed in the next section.

\section{Mitochondrial dysfunction as an outcome of autophagy impairment}

Psychiatric disorders share with neurodegenerative diseases (eg, Parkinson's, Alzheimer's, Huntington's, autism, and amyotrophic lateral sclerosis) both mitochondrial dysfunction $^{37}$ and impaired autophagy. ${ }^{38,39}$ Autophagy is a cellular process required for proper degradation of protein aggregates, damaged subcellular organelles, and pathogens. The classical molecular pathway regulating autophagy is mediated by the mammalian target of rapamicin (mTor). ${ }^{40}$ However, an mTOR-independent and inositol-depletion-dependent pathway was later discovered. ${ }^{41}$ Namely, Sarkar et $\mathrm{al}^{41}$ reported that the three mood stabilizers (lithium, valproic acid, and carbamazepine, all known to reduce inositol levels), ${ }^{42}$ augment autophagy in cell cultures. Zschocke et $\mathrm{al}^{43}$ have shown that tricyclic and selective serotonin reuptake inhibitor antidepressants also enhance autophagy. Correspondingly, antidepressant-like effects were observed in mice treated with the autophagy-inducing compounds, trehalose ${ }^{44}$ and rapamycin. ${ }^{45}$ Similarly, treatment with the typical antipsychotic drug, chlorpromazine, was recently reported to enhance mTORdepended autophagy. ${ }^{46}$ 
Recent studies indicate a reciprocal relationship between mitochondria and autophagy. ${ }^{47-50} \mathrm{Within}$ this context, it has been reported that cells lacking mtDNA or functional oxidative phosphorylation complexes display impaired autophagy ${ }^{51}$ and Suzuki et al reported that in yeast, autophagy is required to retain mtDNA integrity under nitrogen starvation..$^{52}$ These studies suggest a causal relationship between altered autophagy and mitochondrial dysfunction, two characteristics of psychiatric and neurodegenerative disorders.

Mitochondria undergo repeated fission-fusion cycles, crucial to ensure mitochondrial integrity. Fission frequently results in unequal daughter organelles, differing in their membrane potential. The dysfunctional daughter mitochondria is degraded by mithophagy, a cargo-mediated type of autophagy specific to mitochondria. ${ }^{18,53}$ Impairment of fission-fusion cycles or aberrant autophagy would result in accumulation of damaged mitochondria in the cell, gradually reaching mitochondrial threshold. ${ }^{53-55}$ Thus, it is plausible that compromised autophagy or impairment in fission-fusion cycles are causative factors of mitochondrial dysfunction.

\section{Mitochondrial dysfunction as an outcome of a lifestyle}

Exposure to smoking and drugs of abuse (eg, amphetamines, alcohol) is known to induce oxidative stress and/ or mitochondrial dysfunction. ${ }^{56-61}$ These findings are highly important in view of the high incidence of comorbidity between psychiatric disorders and substance abuse, ${ }^{60,62-64}$ yet it is unclear whether there is a causative relationship between the two. In addition, psychiatric disorders often involve disturbances in eating and sleeping patterns, ${ }^{65-67}$ also shown to impair mitochondrial function. ${ }^{68-71}$ Thus, it is possible that at least in some cases, mitochondria-related alterations observed in psychiatric patients are an epiphenomenon, related to disease-induced lifestyle and behavior, rather than a primary etiological factor involved in disease initiation and progression.

\section{Psychiatric disorders - specificity of mitochondrial dysfunction Regional specificity}

Ben-Shachar et al $^{2}$ addressed the issue of disease-specificity of mitochondrial complex I abnormalities. Using postmortem brain specimens, the authors compared the expression level of some of the complex I subunits (NDUFV1, NDUFV2, NDUFS1) in four brain regions of MD, BP, and SCZ patients vs healthy subjects. All three complex I subunits studied showed some extent of differential expression in subjects with the different disorders. Interestingly, a different profile of changes characterized the different disorders. In the striatum, decreased expression of the three subunits was observed in SCZ but not in BP or MD patients. Contrarily, in the cerebellum, differential expression was observed in $\mathrm{BP}$ and MD but not SCZ patients. Likewise, in the prefrontal cortex, at least one of the subunits exhibited decreased expression in SCZ and MD, but not in BP patients. Intriguingly, the direction of the change of NDUFV1 and NDUFV2 was opposite in the striatum vs the parieto-occipital cortex region, and the expression of NDUFS1 was not altered in the prefrontal cortex in either of the disorders. Although stemming from a small sample size ( $n=15$ /group), these results suggest that while mitochondrial dysfunction is a common characteristic of distinct psychiatric disorders, the particular profiles differ in magnitude and temporal occurrence. Curiously, contradicting findings showing upregulation of the three complex I subunits were reported in the blood cells of SCZ patients. ${ }^{72-75}$

\section{Magnitude specificity}

It is worth noting that different phenotypes are obtained following treatment with high vs low doses of the complex I inhibitor, rotenone. Administration of high rotenone doses is used to model Parkinson's disease in mice. ${ }^{76}$ The mice exhibit an impaired motor function, protein aggregation in the brain, and death of dopaminergic neurons. Contrarily, treatment with low rotenone doses had no effect on motor function or the well-being of mice but affected behavioral paradigms related to manic and depressive symptoms. ${ }^{34}$

\section{The comorbidity of psychiatric and mitochondrial disorders}

The term "mitochondrial disorders" refers to the disorders arising due to alteration in mitochondrial function. Several aspects make mitochondria unique among other subcellular organelles and relate to the characteristics of mitochondrial disorders:

1) Mitochondria carry their own DNA (mtDNA) which contains 37 genes encoding for 13 proteins, 22 transfer RNAs (tRNAs), and two ribosomal RNAs (rRNAs). ${ }^{77}$ The majority of the mitochondrial proteins, including most of the subunits of the complexes of oxidative phosphorylation, are encoded by nuclear DNA (nDNA). All 13 proteins encoded by mtDNA belong to oxidative phosphorylation complexes (with the exception of complex II, which is assembled entirely from proteins encoded by nDNA). 
2) Mitochondria are maternally inherited. ${ }^{77}$ As such, many of the mitochondrial disorders, particularly those induced by mtDNA mutations, are characterized by maternal transmission. ${ }^{78}$

3) With some exceptions, each cell contains numerous mitochondria and thousands of copies of mtDNA which may be similar (a condition designated homoplasmy) or different from each other (heteroplasmy). ${ }^{78}$ Since numerous mitochondria coexist in a single cell, cells are relatively resistant to mtDNA mutations. The latter will result in a pathological phenotype when a mitochondrial threshold is reached. ${ }^{54}$

4) mtDNA replication is separate from that of nDNA and is persistent even in nondividing cells. ${ }^{79}$ The polymerase responsible for mtDNA replication, $P O L G,{ }^{77}$ is encoded by nDNA. Mutations in $P O L G$ affecting its proofreading function result in accumulating mutations and deletions in mtDNA. ${ }^{32}$ Increased frequency of the common mtDNA4977 deletion was reported in the brains of BP patients in one study, ${ }^{80}$ but was not replicated by others. ${ }^{14,81-83}$ Interestingly, although not supporting an increase in mtDNA deletions in BP, Kakiuchi et $\mathrm{al}^{81}$ reported significant upregulation of $P O L G$ in the frontal cortex of BP subjects.

Chronic progressive external ophthalmoplegia (CPEO) is a mitochondrial disorder characterized by numerous neuromuscular symptoms. CPEO may be induced by a heterozygous mutation in the proofreading segment of POLG. ${ }^{32}$ Several cases of subjects with CPEO and other mitochondrial disorders and comorbid mood disorders have been recorded. ${ }^{32,84-86}$ Similar homozygous (and to a smaller extent heterozygous) mutations cause motor symptoms in mice ${ }^{87}$ In addition to motor dysfunction, these mice exhibit age-dependent increase in the number of mtDNA deletions, specifically in brain and muscle, ${ }^{87}$ providing a potential link between CPEO and psychiatric disorders.

Are psychiatric disorders related to maternal transmission? Involvement of mtDNA mutations in the etiology of psychiatric disorders would have led to maternal transmission. An early study based on 31 pedigrees reported maternal transmission of BP and therefore suggested the involvement of mtDNA in the pathophysiology of the disorder. ${ }^{88}$ Although maternal transmission of psychiatric disorders was supported in some studies of both $\mathrm{BP}^{89}$ and $\mathrm{SCZ},{ }^{90}$ these findings were not replicated in a study of BP II patients..$^{91}$ A paternal transmission mode was suggested by others ${ }^{92,93}$ and Kirk et a ${ }^{93}$ suggested that a negative selection against maternal transmission occurs in BP. The authors sequenced 23 mitochondrial common variants in BP I patients and control subjects
(94 subjects/group). While no difference in the frequencies of mitochondrial haplotypes was found between the groups, a higher genetic distance (ie, dissimilarity between the haplotypes) was found among BP I patients. Since mitochondria are maternally inherited, the authors concluded that a mild negative selection against maternal transmission takes place in this disease. The authors hypothesized that the negative selection is a result of slightly decreased fitness of embryos presented with mutated mtDNA, resulting in increased chances for extinction of the lineage. ${ }^{93}$

\section{Different studies, similar subjects}

An additional point that should be considered when reviewing the literature or performing meta-analysis is the reuse of the same samples across different studies. ${ }^{94}$ This issue is particularly important in studies involving postmortem brain tissue, due to the rarity of these samples. For example, many of the studies reporting decreased expression of mitochondrial genes in BP, SCZ, and MD used samples from the Stanley Foundation Brain Collection ${ }^{1,2,5,16,81-83}$ or the Harvard Brain Tissue Resource Center. ${ }^{3,8}$ Thus, while at first glance downregulation of mitochondrial genes seems to be highly reproducible in numerous studies, in fact, it is an observation made based on repeated analyses of three small cohorts of subjects (the Stanley Foundation Brain Collection is comprised of two collections - the Neuropathology Consortium Collection and the Array Collection, analyzed independently or together in the different studies).

It is bothersome that studies based on the same cohorts find dissimilar lists of differentially expressed genes ${ }^{94}$ and, in some cases, even contradicting results. For example, samples of the Stanley Foundation Brain Collection studied by Sabunciyan et $\mathrm{l}^{82}$ were also included in Fuke el al's study ${ }^{83}$ study; nevertheless, Sabunciyan et al ${ }^{82}$ found a significantly lower incidence of mtDNA4977 deletion in BP females vs males, while a higher incidence was reported by Fuke et al.$^{83}$ Similarly, no downregulated mitochondrial genes were found in the Stanley Foundation Brain Collection samples by Iwamoto et al, ${ }^{95}$ contradicting other studies using the same cohort. ${ }^{2,5,16}$ These discrepancies suggest that mitochondrial abnormalities might be involved in some but not all patients with psychiatric disorders, and an outcome of a study based on a small sample size is strongly dependent on the particular samples included in study ${ }^{83}$

\section{Conclusion}

Numerous studies provide evidence for the involvement of mitochondrial dysfunction in psychiatric disorders. However, interpretation of these findings should be done with caution. 
Reuse of samples in different studies should be considered. If the same subjects are being tested over and over, it is expected that the studies would find similar results. Moreover, at this point, the causal relationship between psychiatric disorders and mitochondrial alterations remains unclear. Recent findings regarding impaired autophagy in psychiatric and neurodegenerative disorders raise the possibility that at least in some cases, mitochondrial dysfunction might be an outcome of impaired autophagy.

Can different psychiatric disorders with distinct symptoms and drug responsiveness result from similar etiological factors? One possibility is that mitochondrial dysfunction induces vulnerability of brain cells (eg, glia and neurons) to other disease-specific factors. It is also possible that impairment of mitochondrial function is region specific, or that cell susceptibility varies among different brain cells eg, dopaminergic neurons in substantia nigra are extremely sensitive to impaired oxidative phosphorylation due to high energy requirement. Alternatively, mitochondrial dysfunction can be an epiphenomenon related to frequent characteristics of psychiatric patients such as smoking, drug abuse, and disturbed eating and sleeping.

Another issue that remains to be clarified is which of the diverse mitochondrial functions is altered in the different psychiatric disorders. Is it energy production, calcium buffering, or increased production of reactive oxygen species? Without understanding the functional impact of "mitochondrial dysfunction" no adequate attempt for targeted therapy at this level can be made.

\section{Disclosure}

The authors report no conflicts of interest in this work.

\section{References}

1. Sun X, Wang JF, Tseng M, Young LT. Downregulation in components of the mitochondrial electron transport chain in the postmortem frontal cortex of subjects with bipolar disorder. J Psychiatry Neurosci. 2006;31(3):189-196.

2. Ben-Shachar D, Karry R. Neuroanatomical pattern of mitochondrial complex I pathology varies between schizophrenia, bipolar disorder and major depression. PLoS One. 2008;3(11):e3676.

3. Konradi C, Eaton M, MacDonald ML, Walsh J, Benes FM, Heckers S. Molecular evidence for mitochondrial dysfunction in bipolar disorder. Arch Gen Psychiatry. 2004;61(3):300-308.

4. Prabakaran S, Swatton JE, Ryan MM, et al. Mitochondrial dysfunction in schizophrenia: evidence for compromised brain metabolism and oxidative stress. Mol Psychiatry. 2004;9(7):684-697.

5. Altar CA, Jurata LW, Charles V, et al. Deficient hippocampal neuron expression of proteasome, ubiquitin, and mitochondrial genes in multiple schizophrenia cohorts. Biol Psychiatry. 2005;58(2):85-96.

6. Kato T, Kato N. Mitochondrial dysfunction in bipolar disorder. Bipolar Disord. 2000;2(3 Pt 1):180-190.

7. Uranova N, Orlovskaya D, Vikhreva O, et al. Electron microscopy of oligodendroglia in severe mental illness. Brain Res Bull. 2001;55(5): 597-610.
8. Cataldo AM, McPhie DL, Lange NT, et al. Abnormalities in mitochondrial structure in cells from patients with bipolar disorder. Am J Pathol. 2010;177(2):575-585.

9. Gardner A, Boles RG. Beyond the serotonin hypothesis: mitochondria, inflammation and neurodegeneration in major depression and affective spectrum disorders. Prog Neuropsychopharmacol Biol Psychiatry. 2011;35(3):730-743.

10. Dager SR, Friedman SD, Parow A, et al. Brain metabolic alterations in medication-free patients with bipolar disorder. Arch Gen Psychiatry. 2004;61(5):450-458.

11. Regenold WT, Phatak P, Marano CM, Sassan A, Conley RR, Kling MA. Elevated cerebrospinal fluid lactate concentrations in patients with bipolar disorder and schizophrenia: implications for the mitochondrial dysfunction hypothesis. Biol Psychiatry. 2009;65(6):489-494.

12. Du F, Cooper AJ, Thida T, et al. In vivo evidence for cerebral bioenergetic abnormalities in schizophrenia measured using 31P magnetization transfer spectroscopy. JAMA Psychiatry. 2014;71(1):19-27.

13. Frey BN, Stanley JA, Nery FG, et al. Abnormal cellular energy and phospholipid metabolism in the left dorsolateral prefrontal cortex of medication-free individuals with bipolar disorder: an in vivo $1 \mathrm{H} \mathrm{MRS}$ study. Bipolar Disord. 2007;9 Suppl 1:119-127.

14. Cavelier L, Jazin EE, Eriksson I, et al. Decreased cytochrome-c oxidase activity and lack of age-related accumulation of mitochondrial DNA deletions in the brains of schizophrenics. Genomics. 1995;29(1):217-224.

15. Maurer I, Zierz S, Möller H. Evidence for a mitochondrial oxidative phosphorylation defect in brains from patients with schizophrenia. Schizophr Res. 2001;48(1):125-136.

16. Andreazza AC, Shao L, Wang JF, Young LT. Mitochondrial complex I activity and oxidative damage to mitochondrial proteins in the prefrontal cortex of patients with bipolar disorder. Arch Gen Psychiatry. 2010;67(4): 360-368.

17. Chang DT, Honick AS, Reynolds IJ. Mitochondrial trafficking to synapses in cultured primary cortical neurons. J Neurosci. 2006;26(26): 7035-7045.

18. Sheng ZH. Mitochondrial trafficking and anchoring in neurons: New insight and implications. J Cell Biol. 2014;204(7):1087-1098.

19. Glantz LA, Lewis DA. Decreased dendritic spine density on prefrontal cortical pyramidal neurons in schizophrenia. Arch Gen Psychiatry. 2000;57(1):65-73

20. Broadbelt K, Byne W, Jones LB. Evidence for a decrease in basilar dendrites of pyramidal cells in schizophrenic medial prefrontal cortex. Schizophr Res. 2002;58(1):75-81.

21. Jou SH, Chiu NY, Liu CS. Mitochondrial dysfunction and psychiatric disorders. Chang Gung Med J. 2009;32(4):370-379.

22. Rezin GT, Amboni G, Zugno AI, Quevedo J, Streck EL. Mitochondrial dysfunction and psychiatric disorders. Neurochem Res. 2009;34(6): 1021-1029.

23. Scaglia F. The role of mitochondrial dysfunction in psychiatric disease. Dev Disabil Res Rev. 2010;16(2):136-143.

24. Clay HB, Sillivan S, Konradi C. Mitochondrial dysfunction and pathology in bipolar disorder and schizophrenia. Int J Dev Neurosci. 2011;29(3):311-324.

25. Friel DD, Tsien RW. An FCCP-sensitive Ca2+ store in bullfrog sympathetic neurons and its participation in stimulus-evoked changes in [Ca2+]i. J Neurosci. 1994;14(7):4007-4024.

26. Rizzuto R, Pinton $\mathrm{P}$, Carrington W, et al. Close contacts with the endoplasmic reticulum as determinants of mitochondrial $\mathrm{Ca} 2+$ responses. Science. 1998;280(5370):1763-1766.

27. Gunter TE, Gunter KK. Uptake of calcium by mitochondria: transport and possible function. IUBMB Life. 2001;52(3-5):197-204.

28. Wang X. The expanding role of mitochondria in apoptosis. Genes Dev. 2001;15(22):2922-2933.

29. Kato T. Role of mitochondrial DNA in calcium signaling abnormality in bipolar disorder. Cell Calcium. 2008;44(1):92-102.

30. Perova T, Wasserman MJ, Li PP, Warsh JJ. Hyperactive intracellular calcium dynamics in B lymphoblasts from patients with bipolar I disorder. Int J Neuropsychopharmacol. 2008;11(2):185-196. 
31. Uemura T, Green M, Corson TW, Perova T, Li PP, Warsh JJ. Bcl-2 SNP rs956572 associates with disrupted intracellular calcium homeostasis in bipolar I disorder. Bipolar Disord. 2011;13(1):41-51.

32. Kasahara T, Kubota M, Miyauchi T, et al. Mice with neuron-specific accumulation of mitochondrial DNA mutations show mood disorderlike phenotypes. Mol Psychiatry. 2006;11(6):577-593, 523.

33. Kubota M, Kasahara T, Nakamura T, Ishiwata M, Miyauchi T, Kato $\mathrm{T}$. Abnormal $\mathrm{Ca} 2+$ dynamics in transgenic mice with neuronspecific mitochondrial DNA defects. $J$ Neurosci. 2006;26(47): 12314-12324.

34. Toker L, Bersudsky Y, Plaschkes I, et al. Inositol-related gene knockouts mimic lithium's effect on mitochondrial function. Neuropsychopharmacology. 2014;39(2):319-328.

35. Rezin GT, Furlanetto CB, Scaini G, et al. Fenproporex increases locomotor activity and alters energy metabolism, and mood stabilizers reverse these changes: a proposal for a new animal model of mania. Mol Neurobiol. 2014;49(2):877-892.

36. Streck EL, Scaini G, Jeremias GC, et al. Effects of Mood Stabilizers on Brain Energy Metabolism in Mice Submitted to an Animal Model of Mania Induced by Paradoxical Sleep Deprivation. Neurochem Res. 2015; 40(6):1144-1152.

37. Su B, Wang X, Zheng L, Perry G, Smith MA, Zhu X. Abnormal mitochondrial dynamics and neurodegenerative diseases. Biochim Biophys Acta. 2010;1802(1):135-142.

38. Fornai F, Longone P, Ferrucci M, et al. Autophagy and amyotrophic lateral sclerosis: The multiple roles of lithium. Autophagy. 2008;4(4): $527-530$.

39. Wong E, Cuervo AM. Autophagy gone awry in neurodegenerative diseases. Nat Neurosci. 2010;13(7):805-811.

40. Blommaart EF, Luiken JJ, Blommaart PJ, van Woerkom GM, Meijer AJ. Phosphorylation of ribosomal protein S6 is inhibitory for autophagy in isolated rat hepatocytes. J Biol Chem. 1995;270(5):2320-2326.

41. Sarkar S, Floto RA, Berger Z, et al. Lithium induces autophagy by inhibiting inositol monophosphatase. J Cell Biol. 2005;170:1101-1111.

42. Williams RS, Cheng L, Mudge AW, Harwood AJ. A common mechanism of action for three mood-stabilizing drugs. Nature. 2002;417(6886): 292-295.

43. Zschocke J, Zimmermann N, Berning B, Ganal V, Holsboer F, Rein T. Antidepressant drugs diversely affect autophagy pathways in astrocytes and neurons - dissociation from cholesterol homeostasis. Neuropsychopharmacology. 2011;36(8):1754-1768.

44. Kara NZ, Toker L, Agam G, Anderson GW, Belmaker RH, Einat H. Trehalose induced antidepressant-like effects and autophagy enhancement in mice. Psychopharmacology (Berl). 2013;229(2):367-375.

45. Cleary C, Linde JA, Hiscock KM, et al. Antidepressive-like effects of rapamycin in animal models: Implications for mTOR inhibition as a new target for treatment of affective disorders. Brain Res Bull. 2008;76(5): 469-473.

46. Shin SY, Lee KS, Choi YK, et al. The antipsychotic agent chlorpromazine induces autophagic cell death by inhibiting the Akt/mTOR pathway in human U-87MG glioma cells. Carcinogenesis. 2013;34(9): 2080-2089.

47. Elmore SP, Qian T, Grissom SF, Lemasters JJ. The mitochondrial permeability transition initiates autophagy in rat hepatocytes. FASEB J. 2001; 15(12):2286-2287.

48. Zhang H, Kong X, Kang J, et al. Oxidative stress induces parallel autophagy and mitochondria dysfunction in human glioma U251 cells. Toxicol Sci. 2009;110(2):376-388.

49. Hailey DW, Rambold AS, Satpute-Krishnan P, et al. Mitochondria supply membranes for autophagosome biogenesis during starvation. Cell. 2010;141(4):656-667.

50. Okamoto K. Mitochondria breathe for autophagy. EMBO J. 2011; 30(11):2095-2096.

51. Graef M, Nunnari J. Mitochondria regulate autophagy by conserved signalling pathways. EMBO J. 2011;30(11):2101-2114.
52. Suzuki SW, Onodera J, Ohsumi Y. Starvation induced cell death in autophagy-defective yeast mutants is caused by mitochondria dysfunction. PloS One. 2011;6(2):e17412.

53. Twig G, Hyde B, Shirihai OS. Mitochondrial fusion, fission and autophagy as a quality control axis: the bioenergetic view. Biochim Biophys Acta. 2008;1777(9):1092-1097.

54. Rossignol R, Faustin B, Rocher C, Malgat M, Mazat JP, Letellier T. Mitochondrial threshold effects. Biochem J. 2003;370(Pt 3):751-762.

55. Knott $\mathrm{AB}$, Bossy-Wetzel E. Impairing the mitochondrial fission and fusion balance: a new mechanism of neurodegeneration. Ann N Y Acad Sci. 2008;1147:283-292.

56. Miró O, Alonso JR, Jarreta D, Casademont J, Urbano-Márquez A, Cardellach F. Smoking disturbs mitochondrial respiratory chain function and enhances lipid peroxidation on human circulating lymphocytes. Carcinogenesis. 1999;20(7):1331-1336.

57. Cunha-Oliveira T, Rego AC, Cardoso SM, et al. Mitochondrial dysfunction and caspase activation in rat cortical neurons treated with cocaine or amphetamine. Brain Res. 2006;1089(1):44-54.

58. Song BJ, Moon KH, Upreti VV, Eddington ND, Lee IJ. Mechanisms of MDMA (ecstasy)-induced oxidative stress, mitochondrial dysfunction, and organ damage. Curr Pharm Biotechnol. 2010;11(5):434-443.

59. Wang J, Yuan W, Li MD. Genes and pathways co-associated with the exposure to multiple drugs of abuse, including alcohol, amphetamine/ methamphetamine, cocaine, marijuana, morphine, and/or nicotine: a review of proteomics analyses. Mol Neurobiol. 2011;44(3):269-286.

60. Nunes SO, Vargas HO, Prado E, et al. The shared role of oxidative stress and inflammation in major depressive disorder and nicotine dependence. Neurosci Biobehav Rev. 2013;37(8):1336-1345.

61. Song BJ, Akbar M, Abdelmegeed MA, et al. Mitochondrial dysfunction and tissue injury by alcohol, high fat, nonalcoholic substances and pathological conditions through post-translational protein modifications. Redox Biol. 2014;3:109-123.

62. Regier DA, Farmer ME, Rae DS, et al. Comorbidity of mental disorders with alcohol and other drug abuse. Results from the Epidemiologic Catchment Area (ECA) Study. JAMA. 1990;264(19):2511-2518.

63. Kessler RC, Crum RM, Warner LA, Nelson CB, Schulenberg J, Anthony JC. Lifetime co-occurrence of DSM-III-R alcohol abuse and dependence with other psychiatric disorders in the National Comorbidity Survey. Arch Gen Psychiatry. 1997;54(4):313-321.

64. Dierker LC, Avenevoli S, Stolar M, Merikangas KR. Smoking and depression: an examination of mechanisms of comorbidity. Am J Psychiatry. 2002;159(6):947-953.

65. Benca RM, Obermeyer WH, Thisted RA, Gillin JC. Sleep and psychiatric disorders. A meta-analysis. Arch Gen Psychiatry. 1992;49(8):651-668; discussion 669-670.

66. Ford DE, Kamerow DB. Epidemiologic study of sleep disturbances and psychiatric disorders. An opportunity for prevention? JAMA. 1989;262(11):1479-1484

67. Ohayon MM, Roth T. Place of chronic insomnia in the course of depressive and anxiety disorders. $J$ Psychiatr Res. 2003;37(1):9-15.

68. Cirelli C. How sleep deprivation affects gene expression in the brain: a review of recent findings. J Appl Physiol (1985). 2002;92(1): 394-400.

69. Andreazza AC, Andersen ML, Alvarenga TA, et al. Impairment of the mitochondrial electron transport chain due to sleep deprivation in mice. J Psychiatr Res. 2010;44(12):775-780.

70. Cardinali DP, Pagano ES, Scacchi Bernasconi PA, Reynoso R, Scacchi P. Melatonin and mitochondrial dysfunction in the central nervous system. Horm Behav. 2013;63(2):322-330.

71. Awad S, Constantin-Teodosiu D, Macdonald IA, Lobo DN. Short-term starvation and mitochondrial dysfunction - a possible mechanism leading to postoperative insulin resistance. Clin Nutr. 2009;28(5):497-509.

72. Dror N, Klein E, Karry R, et al. State-dependent alterations in mitochondrial complex I activity in platelets: a potential peripheral marker for schizophrenia. Mol Psychiatry. 2002;7(9):995-1001. 
73. Taurines R, Thome J, Duvigneau JC, et al. Expression analyses of the mitochondrial complex I 75-kDa subunit in early onset schizophrenia and autism spectrum disorder: increased levels as a potential biomarker for early onset schizophrenia. Eur Child Adolesc Psychiatry. 2010;19(5):441-448.

74. Mehler-Wex C, Duvigneau JC, Hartl RT, Ben-Shachar D, Warnke A, Gerlach M. Increased mRNA levels of the mitochondrial complex I 75-kDa subunit. A potential peripheral marker of early onset schizophrenia? Eur Child Adolesc Psychiatry. 2006;15(8):504-507.

75. Akarsu S, Torun D, Bolu A, et al. Mitochondrial complex I and III gene mRNA levels in schizophrenia, and their relationship with clinical features. J Mol Psychiatry. 2014;2(1):6.

76. Cannon JR, Tapias V, Na HM, Honick AS, Drolet RE, Greenamyre JT. A highly reproducible rotenone model of Parkinson's disease. Neurobiol Dis. 2009;34(2):279-290.

77. Taanman JW. The mitochondrial genome: structure, transcription, translation and replication. Biochim Biophys Acta. 1999;1410(2):103-123.

78. Holt IJ, Harding AE, Morgan-Hughes JA. Deletions of muscle mitochondrial DNA in patients with mitochondrial myopathies. Nature. 1988;331(6158):717-719.

79. Schapira AH. Mitochondrial disease. Lancet. 2006;368(9529):70-82.

80. Kato T, Stine OC, McMahon FJ, Crowe RR. Increased levels of a mitochondrial DNA deletion in the brain of patients with bipolar disorder. Biol Psychiatry. 1997;42(10):871-875.

81. Kakiuchi C, Ishiwata M, Kametani M, Nelson C, Iwamoto K, Kato T. Quantitative analysis of mitochondrial DNA deletions in the brains of patients with bipolar disorder and schizophrenia. Int J Neuropsychopharmacol. 2005;8(4):515-522.

82. Sabunciyan S, Kirches E, Krause G, et al. Quantification of total mitochondrial DNA and mitochondrial common deletion in the frontal cortex of patients with schizophrenia and bipolar disorder. J Neural Transm. 2007;114(5):665-674.

83. Fuke S, Kametani M, Kato T. Quantitative analysis of the 4977-bp common deletion of mitochondrial DNA in postmortem frontal cortex from patients with bipolar disorder and schizophrenia. Neurosci Lett. 2008;439(2):173-177.
84. Inczedy-Farkas G, Remenyi V, Gal A, et al. Psychiatric symptoms of patients with primary mitochondrial DNA disorders. Behav Brain Funct. 2012;8:9.

85. Anglin RE, Tarnopolsky MA, Mazurek MF, Rosebush PI. The psychiatric presentation of mitochondrial disorders in adults. J Neuropsychiatry Clin Neurosci. 2012;24(4):394-409.

86. Rapinesi C, Janiri D, Kotzalidis GD, et al. Mitochondrial myopathy and comorbid major depressive disorder: effectiveness of dTMS on gait and mood symptoms. Gen Hosp Psychiatry. 2015;37(3):274.e7-e9.

87. Fuke S, Kametani M, Yamada K, et al. Heterozygous Polg mutation causes motor dysfunction due to mtDNA deletions. Ann Clin Transl Neurol. 2014;1(11):909-920.

88. McMahon FJ, Stine OC, Meyers DA, Simpson SG, DePaulo JR. Patterns of maternal transmission in bipolar affective disorder. Am J Hum Genet. 1995;56(6):1277-1286.

89. Gershon ES, Badner JA, Detera-Wadleigh SD, Ferraro TN, Berrettini WH. Maternal inheritance and chromosome 18 allele sharing in unilineal bipolar illness pedigrees. Am J Med Genet. 1996;67(2):202-207.

90. Amar S, Shamir A, Ovadia O, et al. Mitochondrial DNA HV lineage increases the susceptibility to schizophrenia among Israeli Arabs. Schizophr Res. 2007;94(1-3):354-358.

91. Kato T, Winokur G, Coryell W, et al. Failure to demonstrate parentof-origin effect in transmission of bipolar II disorder. $J$ Affect Disord. 1998;50(2-3):135-141.

92. Kornberg JR, Brown JL, Sadovnick AD, et al. Evaluating the parent-oforigin effect in bipolar affective disorder. Is a more penetrant subtype transmitted paternally? J Affect Disord. 2000;59(3):183-192.

93. Kirk R, Furlong RA, Amos W, et al. Mitochondrial genetic analyses suggest selection against maternal lineages in bipolar affective disorder. Am J Hum Genet. 1999;65(2):508-518.

94. Elashoff M, Higgs BW, Yolken RH, et al. Meta-analysis of 12 genomic studies in bipolar disorder. J Mol Neurosci. 2007;31(3):221-243.

95. Iwamoto K, Kakiuchi C, Bundo M, Ikeda K, Kato T. Molecular characterization of bipolar disorder by comparing gene expression profiles of postmortem brains of major mental disorders. Mol Psychiatry. 2004;9(4):406-416.
Neuropsychiatric Disease and Treatment

\section{Publish your work in this journal}

Neuropsychiatric Disease and Treatment is an international, peerreviewed journal of clinical therapeutics and pharmacology focusing on concise rapid reporting of clinical or pre-clinical studies on a range of neuropsychiatric and neurological disorders. This journal is indexed on PubMed Central, the 'PsycINFO' database and CAS,

\section{Dovepress}

and is the official journal of The International Neuropsychiatric Association (INA). The manuscript management system is completely online and includes a very quick and fair peer-review system, which is all easy to use. Visit http://www.dovepress.com/testimonials.php to read real quotes from published authors. 